\title{
Development of Radar Absorbing Nano Crystals under Thermal Irradiation
}

\author{
Rahul Sharma ${ }^{a}$, Ramesh C Agarwala ${ }^{b}$ and Vijaya Agarwala ${ }^{c}$ \\ Surface Engineering Lab, Metallurgical and Materials Engineering Department, \\ Indian Institute of Technology Roorkee, IITR Roorkee -247 667 (Uttarakhand), INDIA \\ arahuldmt@gmail.com, ${ }^{b}$ ramesfmt@iitr.ernet.in, ${ }^{c}$ vijayfmt@iitr.ernet.in
}

received paper 2.01.2008, received revised paper, 10.02.2008 accepted date, 12.02.2008

Keywords: radar absorbing material, RAM; nano crystal; modified flux method; Ostwald ripening; refection loss, thermal irradiation.

\begin{abstract}
Single phase W-type barium hexaferrite nano crystals of radar absorbing material (RAM) i.e., $\mathrm{BaMe}_{2} \mathrm{Fe}_{16} \mathrm{O}_{27}\left(\mathrm{Me}^{2+}=\mathrm{Fe}^{2+}\right)$ were synthesized by a modified flux method that combines the controlled chemical co-precipitation process for nucleation and complete uniform growth during in-situ annealing with $\mathrm{NaCl}$ flux under vacuum furnace. Uniform structure morphological transformation of nano crystals from spherical to prism faces were noticed after annealing with increasing temperatures from 200 to $1200{ }^{\circ} \mathrm{C}$ for $4 \mathrm{~h}$ in vacuum. XRD results showed the single phase nanocrystals of $\mathrm{BaFe}_{18} \mathrm{O}_{27}$ with increasing crystallanity and size from 10 to $90 \mathrm{~nm}$ during annealing. FESEM and TEM were used to investigate the systematic growth processes of various morphologies of nano crystals. The effect of such systematic morphological transformation of nanocrystals was observed in dielectric, dynamic magnetic and refection loss (RL) properties in $\mathrm{Ku}-$ band (12.4 -18.0 GHz). A significant increment from $-15.23 \mathrm{~dB}$ to $-43.65 \mathrm{~dB}$ with wide range of bandwidth in RL loss is noticed due to the symmetric morphological growth of single phase nano crystals of RAM during annealing. This process of crystal growth, morphology evolution and RL enhancement with respect to increasing temperature were also explained in terms of ostwald ripening and quantum size effect.
\end{abstract}

\section{Introduction}

The electromagnetic interference (EMI) problems have been attracting more attention recently due to the extensive growth in the application of electronic devices such as computer local area networks, mobiles phones, laptops, microwave oven etc [1-3]. EMI can cause severe interruption on electronically controlled systems. Furthermore, larger exposure to microwave energy can be potentially harmful to biological systems and human beings. To overcome EMI problems, it is suggested that electromagnetic wave absorbing materials with the capability of absorbing unwanted electromagnetic signals are to be used. For significant absorption of electromagnetic waves, the radar absorption material (RAM) should have electric and/or magnetic dipoles that interact with the electromagnetic fields in the radiation. Microwave absorption materials from magnetic to dielectric related materials used in a high frequency are particularly noticed. But, pure dielectric or magnetic materials are insufficient for absorbing radiation energy. The efficiency of magnetic-dielectric absorbers is high because the complex permittivity $\left(\varepsilon^{\prime}-j \varepsilon^{\prime \prime}\right)$ and permeability $\left(\mu^{\prime}-j \mu^{\prime \prime}\right)$ differ from zero [4-6]. In general, the suitable values of RAM can be achieved by adding lossy fillers and/or magnetic particles to a light weight that are physically and chemically stable one and of course have a high ability to absorb electromagnetic wave radiation [7-10]. The composite approach has been used to improve various material properties, including mechanical, chemical, structural, optical and electrical/magnetic etc [11-17]. 
To improve performance of various hexaferrites, there have been increasing attentions onto the morphology control of materials as it play very important roles in determining chemical and physical properties of materials [18-24] that is attributed to the novel application. Two general synthesis routes have been explored for chemical synthesis of special morphologies: (1) use of hard templates, which physically confine the size and shape of the growing nano particles [25]; and (2) use of organic compounds during nano particle growth to control its direction and dimension [2628]. Between the two methods, the latter provides effective routes to objects with special morphologies. Various techniques have been developed to prepare nanosized hexaferrite for these purposes. They include the glass crystallization method [29], the wet method [30], the liquid mix technique [31], colloidal methods [32], and so on. The common feature of these methods is the intimate mixing of ions in the atomic level so that subsequent nucleation and crystallization can occur and induce the phase transition at relatively low temperatures. In recent works it has been shown that the aerosol synthesis technique [33, 34] and modified co-precipitation method [17, 35] also appear to be promising methods for the preparation of nanosized particles of unique composition and electromagnetic behavior [24, 36].

This study deals with the development of single phase W-type barium hexaferrite nano crystals produced by modified flux method. Systematic uniform growth of nano crystals with respect to temperature has been investigated under FESEM, XRD and TEM. The effect of such systematic morphological transformation of nanocrystals was observed in dielectric, dynamic magnetic and refection loss (RL) properties in Ku-band (12.4 -18.0 GHz). This process of morphological transformation of nanocrystals that attributed to RL enhancement with respect to increasing temperature were also explained in terms of Ostwald ripening and quantum size effect.

\section{Experimental Procedure}

Synthesize Route. Nanocrystals of W-type barium hexaferrite i.e. $\mathrm{BaFe}_{18} \mathrm{O}_{27}$ were synthesized by using modified flux method. The systematic details of nucleation and growth nano crystals were explained in three steps in figure 1.

In the first stage, all the required salts were desolved separately and further neutralized with $\mathrm{NaOH}$. The precipitation was took place irrespective of $\mathrm{pH}$, but prominent at values of $\mathrm{pH}$ in the range of 10-12 so the temperature was found to be increased from 30 to $80{ }^{\circ} \mathrm{C}$. The color of product of co-precipitation was observed to be light brown. In the second step, the precipitated nanocrystalline powder was mixed thoroughly with $\mathrm{NaCl}$ in $1: 2$ ratios (by weight). For neutralization the number of moles of $\mathrm{NaOH}$ equals number of moles of $\mathrm{Cl}^{-}$ions. During mixing the $\mathrm{NaCl}$ layer was uniformly coated (as a core) around the powder (as a nucleus). As the melting point of $\mathrm{NaCl}$ is around $800{ }^{\circ} \mathrm{C}$ so the temperature of annealing for 'as-synthesized' hexaferrite particles was taken from 200 to $1200{ }^{\circ} \mathrm{C}$ for $4 \mathrm{~h}$ to see the uniform growth.

The $\mathrm{NaCl}$ coated particles were annealed under vacuum for $4 \mathrm{~h}$ at different temperatures of 200 , $400,600,800,1000$ and $1200{ }^{\circ} \mathrm{C}$ to study the growth mechanism involved. Annealing at 800-1200 ${ }^{\circ} \mathrm{C}$, the particles surrounded by molten $\mathrm{NaCl}$ salt and thus, the process of growth is similar to the one taking place in liquid phase sintering with high diffusion rates. This makes the process fast and the hexaferrite particles further crystallize out completely and gives uniform morphology after cooling under vacuum. Then the cooled mixture of nano crystals and $\mathrm{NaCl}$ was washed by the deionized water so $\mathrm{NaCl}$ is desolved and $\mathrm{BaFe}_{18} \mathrm{O}_{27}$ nano crystals filtered out. 


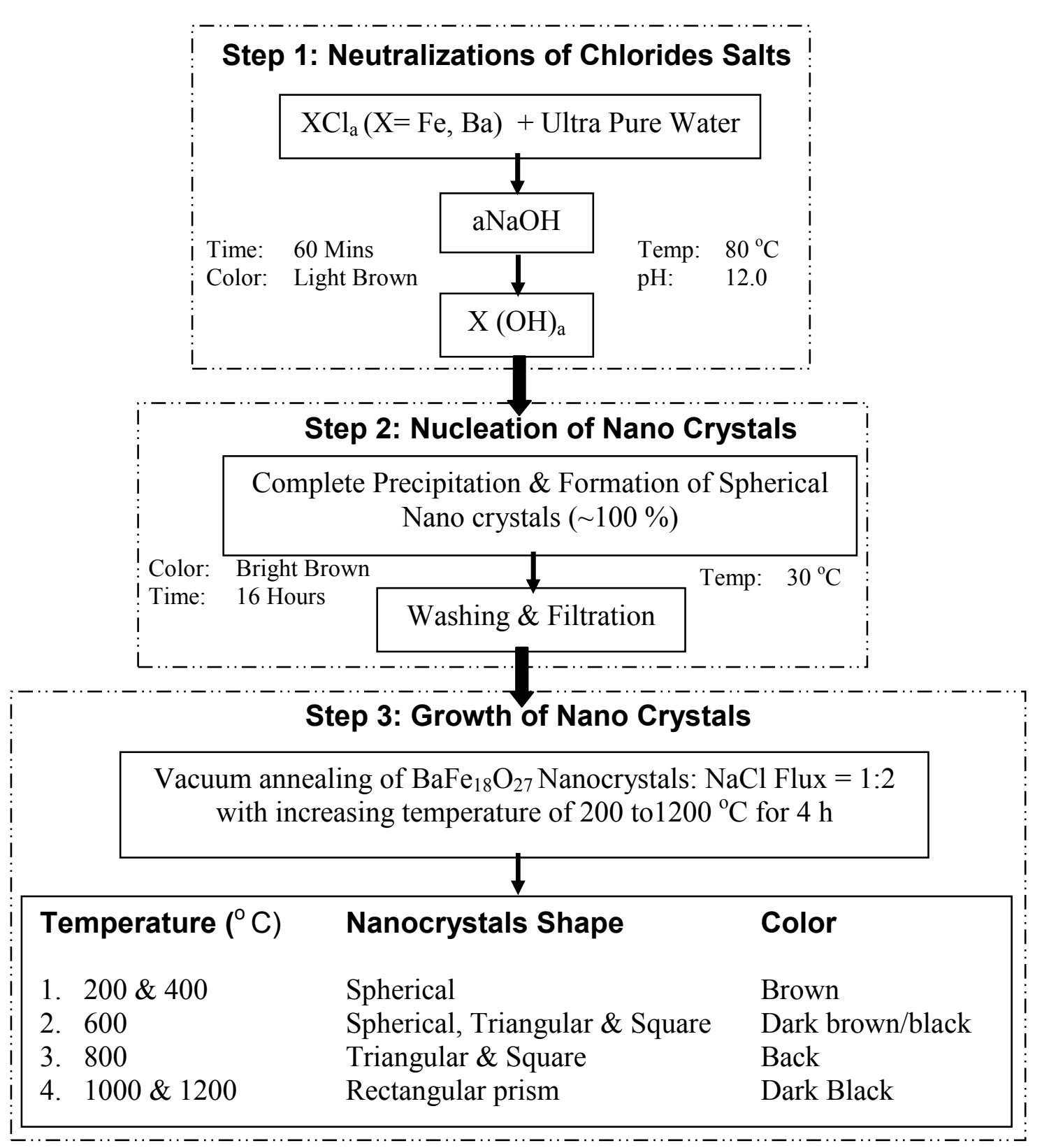

Fig. 1: Schematic representation of nucleation and growth with various morphologies of W-type barium hexaferrite nano crystals.

Characterization Studies. Surface morphologies and elemental composition analysis of all the powder samples were carried out by field emission scanning electron microscope, FESEM, FESEM-EDAX (QUANTA FEG 200 FEI Netherland). For the X-ray diffraction, XRD (Bruker AXS, D8 Advance) was used for phase analysis with $\mathrm{Cu} \mathrm{K} \alpha$ radiation at the diffraction angle (20) ranging from 30 to 60 o. The samples for TEM analysis were dispersed in ethanol with the aid of ultrasound and then applied on carbon coated copper grid, where they were allowed to dry and later viewed under the TEM (Philips, EM 400). For RL measurements, all the nano crystals powder samples were homogeneously dispersed into the polymer $(90 \%$ epoxy resin with $10 \%$ hardener) with a constant weight ratio of 1:10 respectively. The samples of thickness $2 \mathrm{~mm}$ were cured at 90 ${ }^{\circ} \mathrm{C}$ for $4 \mathrm{~h}$ and fabricated on a standard aluminum substrate. The variations of reflection loss versus frequency were studied by measuring the voltage standing-wave ratio (VSWR) on the Ku-band microwave bench. A network analyzer HP 8720B was employed to determine the values of $\varepsilon^{\prime}, \varepsilon^{\prime \prime}$, $\mu^{\prime}$, and $\mu^{\prime \prime}$ at different frequencies by using a reflection/transmission technique. The variation of RL 
versus frequency for all the powders was studied by vector network analyzer and standard horn antennas in anechoic chamber.

\section{Results and Discussion}

XRD Study. The existing phases in the 'as-synthesized' $\mathrm{BaFe}_{18} \mathrm{O}_{27}$ hexaferrite nano crystals along with the phase transformation at various heat treatment stages are characterized by powder XRD in figures 2 (a-g). The XRD patterns for the 'as synthesized' powder and after annealing at 200, 400, $600,800,1000$, and $1200{ }^{\circ} \mathrm{C}$ for 4 hours are shown in figures 2 (b-f) respectively. All the existing diffraction peaks were identified with the corresponding phases for powders (figure 3 ) and are well matched with $\mathrm{BaFe}_{18} \mathrm{O}_{27}$.

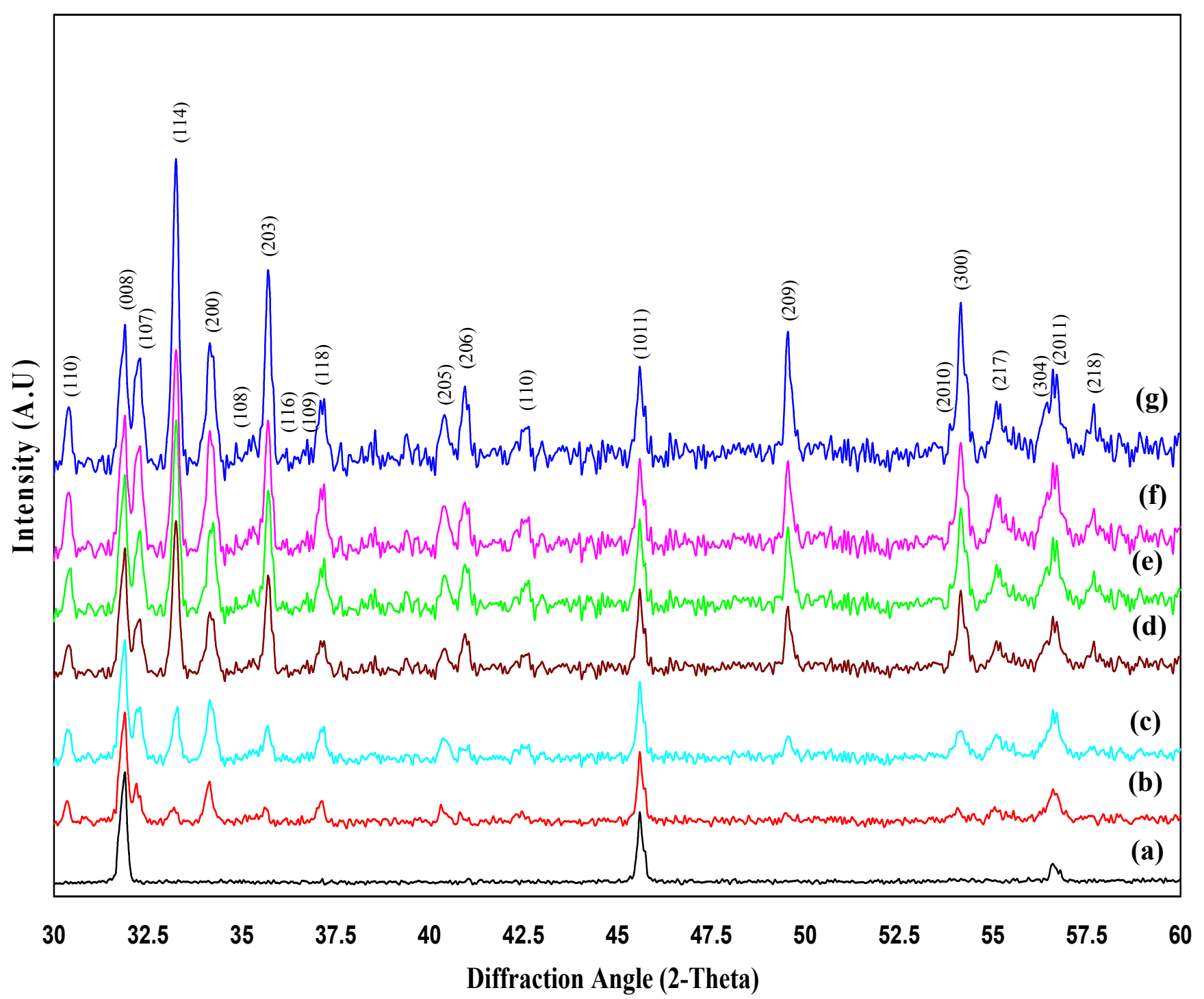

Fig. 2: XRD patterns of single phase $\mathrm{BaFe}_{18} \mathrm{O}_{27}$ hexaferrite nanocrystals (a) As- synthesized and post annealed with $\mathrm{NaCl}$ flux at increasing temperatures (b) 200 (c) 400 (d) 600 (e) 800 (f) $1000(\mathrm{~g}) 1200{ }^{\circ} \mathrm{C}$. 
As synthesized RAM and annealed at $200{ }^{\circ} \mathrm{C}$ powders is not fully amorphous but consist of diffraction peaks due to some spherical nanocrystals in the amorphous phases. XRD patterns of the powders, annealed at relatively low temperatures $\left(400\right.$ and $\left.600{ }^{\circ} \mathrm{C}\right)$ have low intensities peaks for all the phases and but no $\alpha-\mathrm{BaFe}_{2} \mathrm{O}_{4}, \gamma-\mathrm{Fe} 2 \mathrm{O} 3$, or any other intermediate ferrite are observed during the formation that indicated the direct formation of single phase $\mathrm{BaFe}_{18} \mathrm{O}_{27}$ hexaferrite nanocrystals.

It is observed that by annealing around $1000{ }^{\circ} \mathrm{C}$, the crystallinity of single phase is increased considerably and attributes to the complete growth of $\mathrm{BaFe}_{18} \mathrm{O}_{27}$ hexaferrite nano crystals. The average crystallite size is found to increase from $10 \mathrm{~nm}$ to $90 \mathrm{~nm}$ (average particle size, calculated by Scherrer's formula for all the reflections) after annealing in the vacuum furnace at $1200{ }^{\circ} \mathrm{C}$ for $4 \mathrm{~h}$.

FESEM Study. The FESEM micrographs in figures 3 (a-g) show the surface morphologies transformation of $\mathrm{BaFe}_{18} \mathrm{O}_{27}$ nano crystals from spherical to pyramidal faces with respect to the increasing annealing temperature from 80 to $1200{ }^{\circ} \mathrm{C}$ for $4 \mathrm{~h}$. Examining numerous FESEM micrographs of the samples at various stages, it is observed that about $90 \%$ of the spherical nano crystals have transform into the rectangular prism structure and the size of these rectangular prism can be as small as $40 \mathrm{~nm}$ to as large as $90 \mathrm{~nm}$. Figure $3(\mathrm{~g})$ shows FESEM micrographs of nano crystal of pyramidal faces with high geometric symmetry.

To understand the growth mechanism of the pyramidal faces structure, temperature dependent experiments for each set were carried out with $\mathrm{NaCl}$ flux for $4 \mathrm{~h}$ under vacuum. A series of FESEM micrographs in figures 3 (b-g) show the morphology at different annealing temperatures of 200, $400,600,800,1000$ and $1200{ }^{\circ} \mathrm{C}$ corresponding to same reaction time of $4 \mathrm{~h}$, respectively. The aggregated $\mathrm{BaFe}_{18} \mathrm{O}_{27}$ nanocrystals $(\sim 10 \mathrm{~nm})$ have spherical morphology (Fig.3 a) emerged as the initial product.

When prolonged heating with $\mathrm{NaCl}$ for $4 \mathrm{~h}$ is carried out crystallites surface on these aggregated particles are observed (Fig. 3 b). This process of crystal growth and morphological evolution can be described in terms of Ostwald ripening [37], which involves many nano crystals $(\sim 10 \mathrm{~nm})$ form in a system initially but slowly disappear except for a few that grow larger, at the expense of the nano crystals. The nano crystals $(\sim 10 \mathrm{~nm})$ act as "nutrients" for the bigger crystals $(\sim 90 \mathrm{~nm})$. As the larger crystals grow, the area around them is depleted of nano crystals. This is a spontaneous process that occurs because larger crystals are more energetically favored than smaller crystals for further growth. While the formation of many nano crystals is kinetically favored for the nucleation at low temperatures large crystals are thermodynamically favored for growth.

Thus, from a standpoint of kinetics, it is easier to nucleate many nano crystals. However, nano crystals have a larger surface area to volume ratio than large crystals. Molecules on the surface are energetically less stable than the ones already well ordered and packed in the interior. Large crystals, with their greater volume to surface area ratio, represent a lower energy state. Thus, many nano crystals will attain a lower energy state if transformed into large crystals and this is what we observed in FESEM micrographs (Figs. $3 \mathrm{a}-\mathrm{g}$ ). When reaction temperature is increased to $800{ }^{\circ} \mathrm{C}$, most of the products got crystallized having triangular faces of the prism (Fig. 3 e). When the reaction temperature is increased to $1000{ }^{\circ} \mathrm{C}$, rough surfaces of the faces, have been formed (Figs. 3 $\mathrm{f}-\mathrm{g}$ ) that becomes further sharp and smoother at $1200{ }^{\circ} \mathrm{C}$. Thus with increasing reaction temperature, smoother nano crystal faces can be attained for the $\mathrm{BaFe}_{18} \mathrm{O}_{27}$ rectangular prism due to continuous surface flattening (Fig. $3 \mathrm{~g}$ ). 

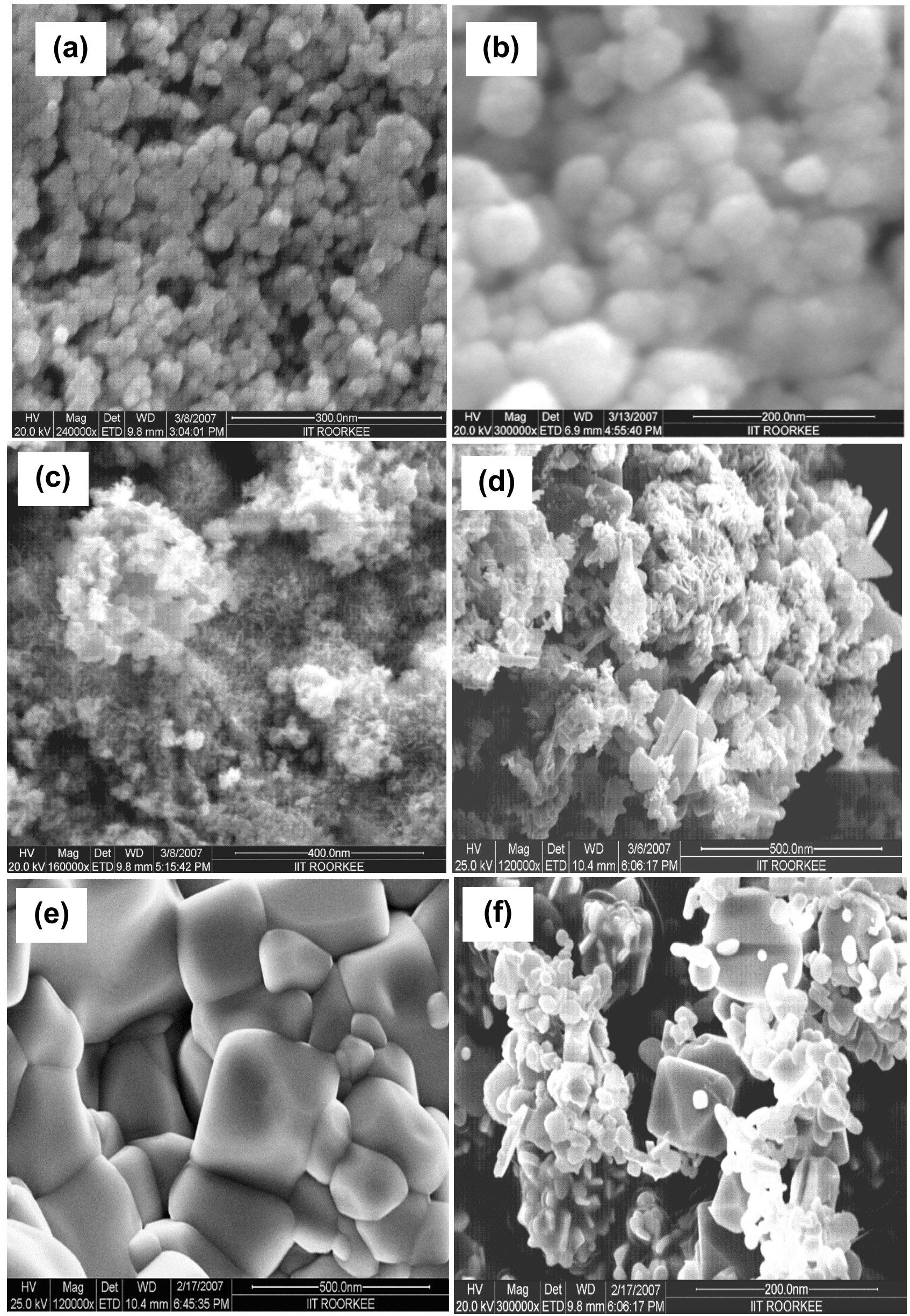


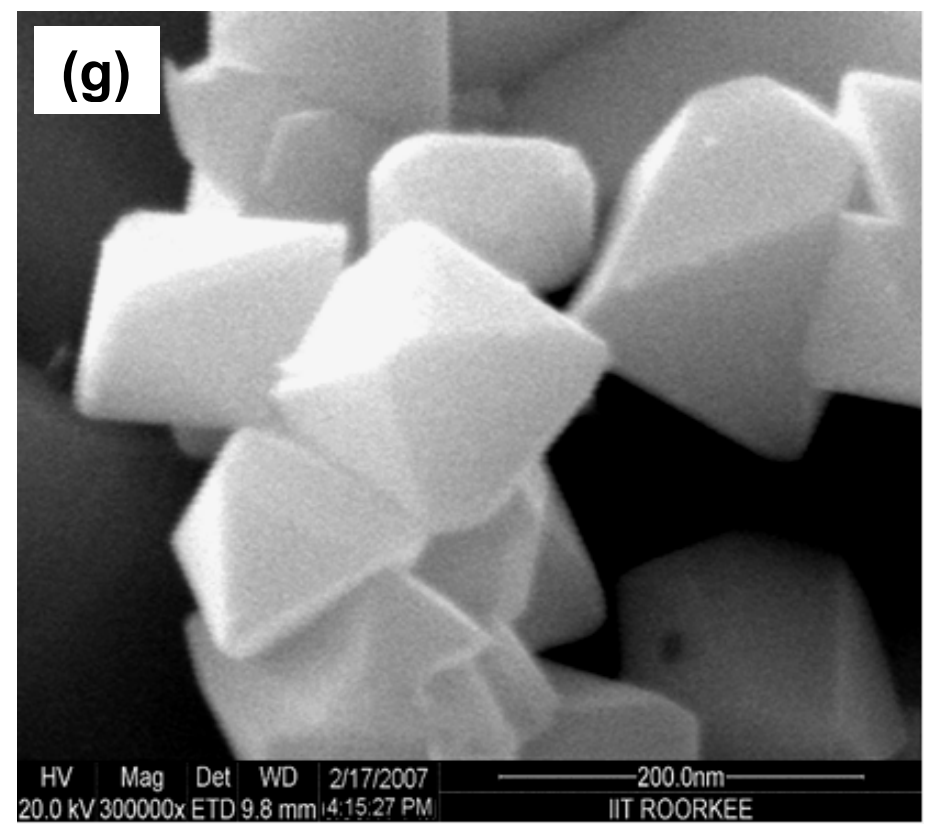

Fig. 3: FESEM micrographs showing the systematic growth of $\mathrm{BaFe}_{16} \mathrm{O}_{27}$ nano crystals (a) assynthesized and annealed with $\mathrm{NaCl}$ flux at (b) 200, (c) 400, (d) 600, (e) 800, (f) 1000 and (g) $1200{ }^{\circ} \mathrm{C}$ for $4 \mathrm{~h}$ in vacuum furnace.

TEM Study. The TEM micrographs with SAD patterns of 'as-synthesized' and vacuum annealed nano crystals at 80 and $600,800,1000,1200{ }^{\circ} \mathrm{C}$ for $4 \mathrm{~h}$ are shown in figures 4 (a-e) respectively. Different morphologies of nano crystals are seen in figure 4 (b). The 'as-synthesized' nano crystalline particles are well dispersed with amorphous particles in the range of 10-12 nm (Fig. 4 a) as its SAD pattern consist of bright spots in amorphous rings. With increasing temperature, nano crystallanity is increasing and finally transforming into single nano crystal of pyramidal shape. A systematic growth of nano crystals can be seen with increasing temperature that attributing to the sharp planes of it. The SAD patterns at $1200{ }^{\circ} \mathrm{C}$ shown in figure 4 (e) are purely single crystalline with the complete growth of nano crystals. The nano crystals annealing at $600{ }^{\circ} \mathrm{C}$ has shown multiple morphologies (Fig. 4 b) i.e. some of the crystals are partially grown (marked with arrow) or metastable stage of nano crystals.
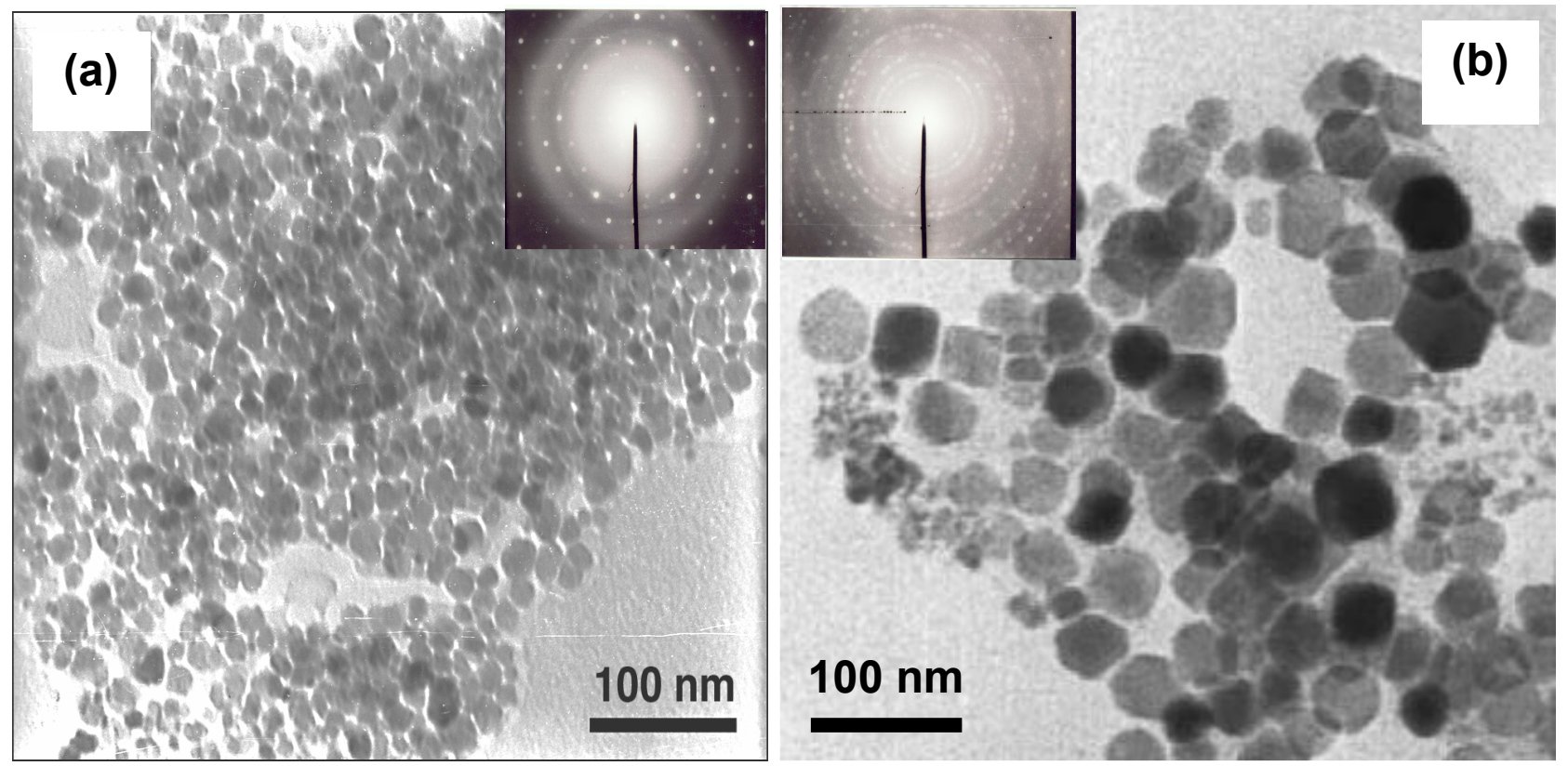


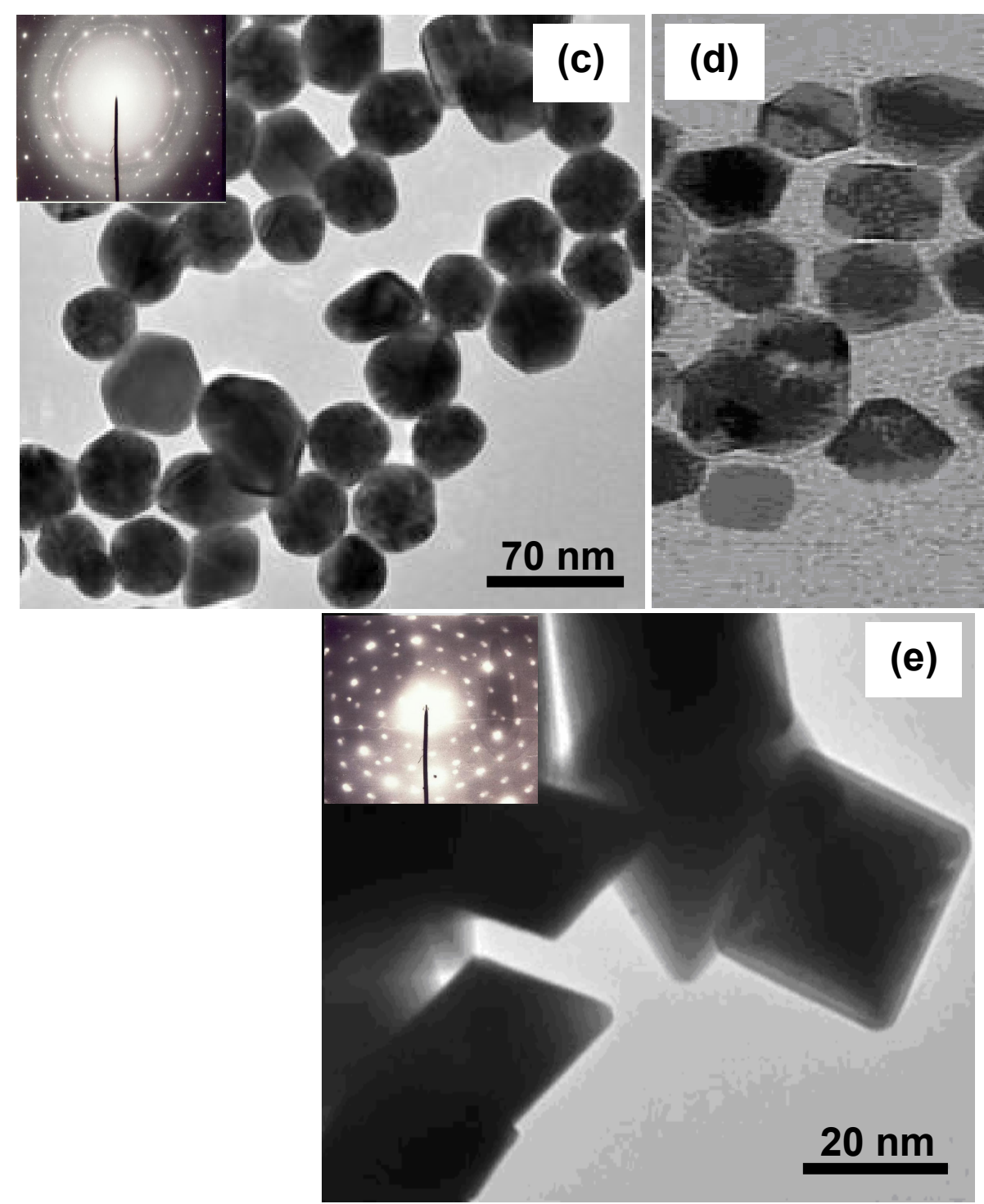

Fig. 4: TEM images with its $\mathrm{SAD}$ showing the systematic growth of $\mathrm{BaFe}_{16} \mathrm{O}_{27}$ nano crystals of (a) as-synthesized spherical and vacuum annealed for $4 \mathrm{~h}$ at (b) 600, (d) 800, (c) 1000 and (d-e) $1200{ }^{\circ} \mathrm{C}$ respectively.

Dielectric and Magnetic Properties. Complex permittivity and permeability represent the dielectric and dynamic magnetic properties of magnetic materials. The real parts $\left(\varepsilon^{\prime}\right.$ and $\left.\mu^{\prime}\right)$ of complex permittivity and permeability symbolize the storage capability of electric and magnetic energy. The imaginary parts $\left(\varepsilon^{\prime \prime}\right.$ and $\left.\mu^{\prime \prime}\right)$ represent the loss of electric and magnetic energy. As a microwave absorber, big imaginary parts of complex permittivity and permeability are expected to reduce with increasing frequency.

The real and imaginary parts of complex permittivity and permeability of all the nano crystals are plotted as a function of frequency in Ku band (12.4-18 GHz) in Fig. 5 (a-d). It is observed that with the increase in annealing temperature from 200 to $1200 \mathrm{oC}$, the complex permittivity and permeability is increasing continuously. Figure 5 (a and c) the $\varepsilon^{\prime}$ and $\mu^{\prime}$ is found to increase from 7.85 to 17.69 and 12.40 to 32.72 respectively at $12.4 \mathrm{GHz}$ and the values remain stable in 14.20 to $18.0 \mathrm{GHz}$. From figure 5 ( $\mathrm{b}$ and $\mathrm{c}$ ), it can be seen that the imaginary parts, $\varepsilon^{\prime \prime}$ and $\mu$ " almost be stable in the entire frequency range during annealing, with some fluctuations for nano crystals annealed at 600 and $800 \mathrm{oC}$. It is observed that uniform morphology (shape and size) is playing most significant role in the dielectric, magnetic and reflection loss properties of the nano crystals. This fluctuation in $\varepsilon^{\prime \prime}$ and $\mu^{\prime \prime}$ at 600 and $800 \mathrm{oC}$ is the metastable stage due to the non uniform shape 
and size distribution of nano crystals. Such fluctuations are also observed for microwave absorption characteristic.
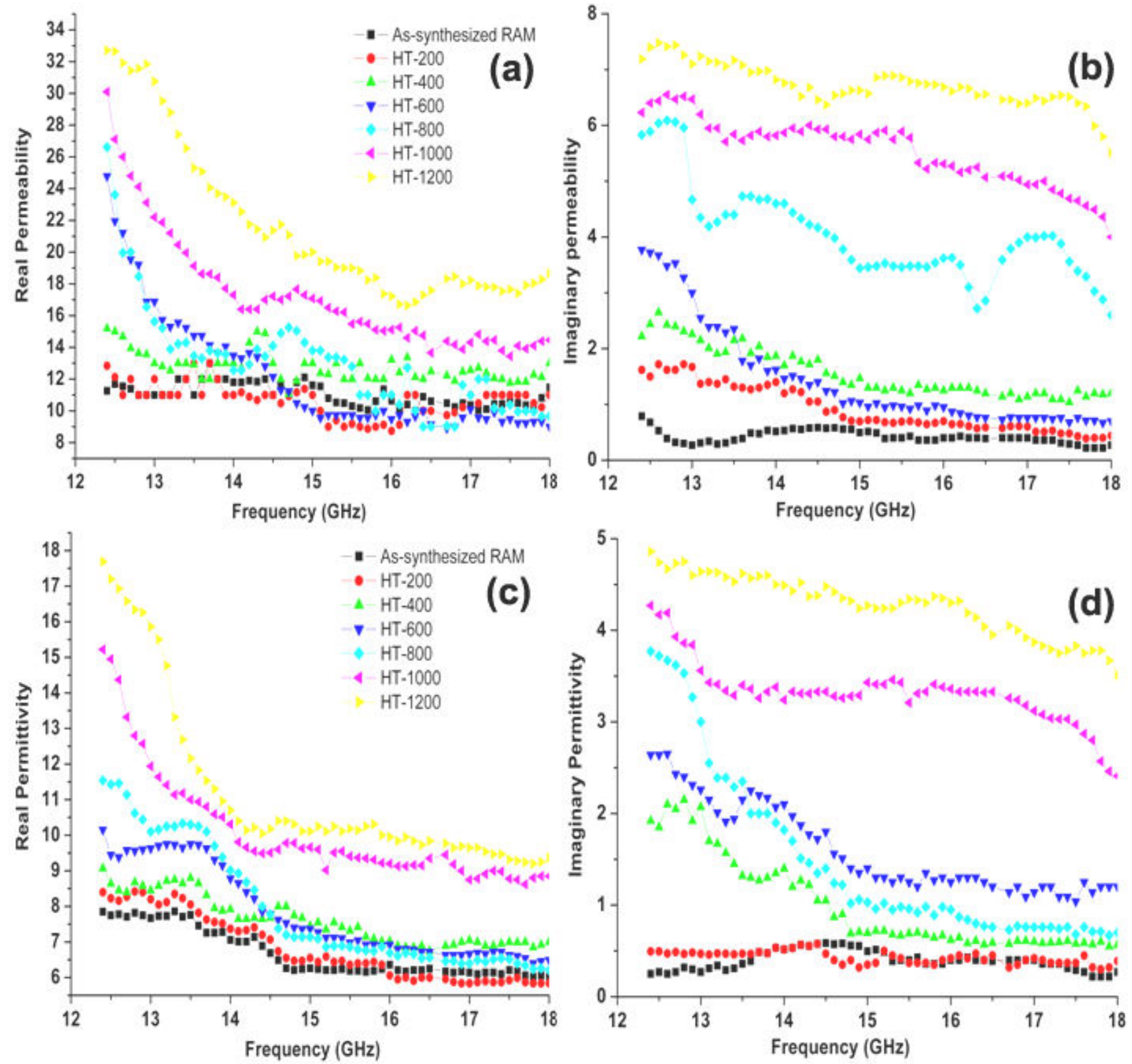

Fig. 5: The complex permittivity (a) real part, $\varepsilon^{\prime}$ (b) imaginary part, $\varepsilon^{\prime \prime}$ and permeability (c) real part, $\mu^{\prime}$ (d) imaginary part, $\mu^{\prime \prime}$ for all the nano crystals (as-synthesized RAM and vacuum annealed at $200,400,600,800,1000$ and $1200{ }^{\circ} \mathrm{C}$ ) as a function of frequency in $\mathrm{Ku}$ band.

Reflection Loss Study. The normalized input impedance $Z_{\text {in }}$ of a metal-backed microwave absorption layer could be obtained from the following expression: $Z_{\text {in }}=\sqrt{ }\left(\varepsilon_{r} / \mu_{r}\right) \tanh [-\mathrm{j}(2 \pi \mathrm{fd} / \mathrm{c}) \sqrt{ }$ $\left(\varepsilon_{r} \mu_{r}\right)$ ], where $\varepsilon_{r}$ and $\mu_{r}$ are the relative permittivity and permeability of the composite medium, $c$ is the velocity of electromagnetic waves in free space, $f$ is the frequency of microwaves, and $d$ is the thickness of the absorber. Accordingly, the reflection loss is associated with $Z_{\text {in }}$ as $\mathrm{RL}(\mathrm{dB})=20 \log$ $\left[\left(Z_{\text {in }}-1\right) /\left(Z_{\text {in }}+1\right)\right][38,39]$. It is reported that the microwave absorption would be improved when particle size is reduced from micron to nano range [40]. 
Table 1: The effect of vacuum annealing onto the morphological transformation and dielectric properties of nanocrystals at minimum frequency $12.4 \mathrm{GHz}$ of $\mathrm{Ku}$ band.

\begin{tabular}{|c|c|c|c|c|c|c|c|c|}
\hline \multirow{2}{*}{\multicolumn{2}{|c|}{$\begin{array}{c}\text { Temperature } \\
\left({ }^{\circ} \mathrm{C}\right)\end{array}$}} & \multicolumn{2}{|c|}{ Morphologies of Nano crystals } & \multicolumn{2}{|c|}{$\begin{array}{c}\text { Complex } \\
\text { permittivity }\end{array}$} & \multicolumn{2}{|c|}{$\begin{array}{c}\text { Complex } \\
\text { permeability }\end{array}$} & \multirow[t]{2}{*}{ Stages } \\
\hline & & $\begin{array}{l}\text { Size } \\
(\mathrm{nm})\end{array}$ & Shapes & $\varepsilon^{\prime}$ & $\varepsilon^{\prime \prime}$ & $\mu^{\prime}$ & $\mu^{\prime \prime}$ & \\
\hline \multicolumn{2}{|c|}{$\begin{array}{c}80 \text { (As } \\
\text { Synthesized) }\end{array}$} & 10 & Regular Spheres & 7.85 & 0.25 & 11.26 & 0.79 & $\begin{array}{l}\text { Most } \\
\text { Stable }\end{array}$ \\
\hline \multirow{6}{*}{ 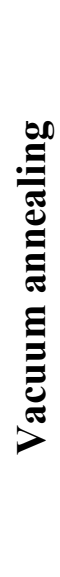 } & 200 & 24 & Irregular Spheres & 8.40 & 0.50 & 12.84 & 1.62 & \multirow{2}{*}{ Stable } \\
\hline & 400 & 35 & $\begin{array}{c}\text { Spherical, } \\
\text { triangular faces } \\
\end{array}$ & 9.07 & 1.92 & 15.19 & 2.22 & \\
\hline & 600 & 40 & Squires, triangular faces & 10.15 & 2.64 & 24.78 & 3.77 & \multirow[b]{2}{*}{$\begin{array}{l}\text { Meta } \\
\text { Stable }\end{array}$} \\
\hline & 800 & 60 & $\begin{array}{c}\text { Spherical, squires } \\
\text { triangular, rectangular } \\
\text { hexagonal }\end{array}$ & 11.54 & 3.77 & 26.16 & 5.83 & \\
\hline & 1000 & 70 & $\begin{array}{l}\text { Triangular, pyramidal } \\
\text { faces }\end{array}$ & 15.22 & 4.27 & 30.10 & 6.23 & Stable \\
\hline & 1200 & 90 & Pyramidal faces & 17.69 & 4.86 & 32.72 & 7.19 & $\begin{array}{l}\text { Most } \\
\text { Stable }\end{array}$ \\
\hline
\end{tabular}

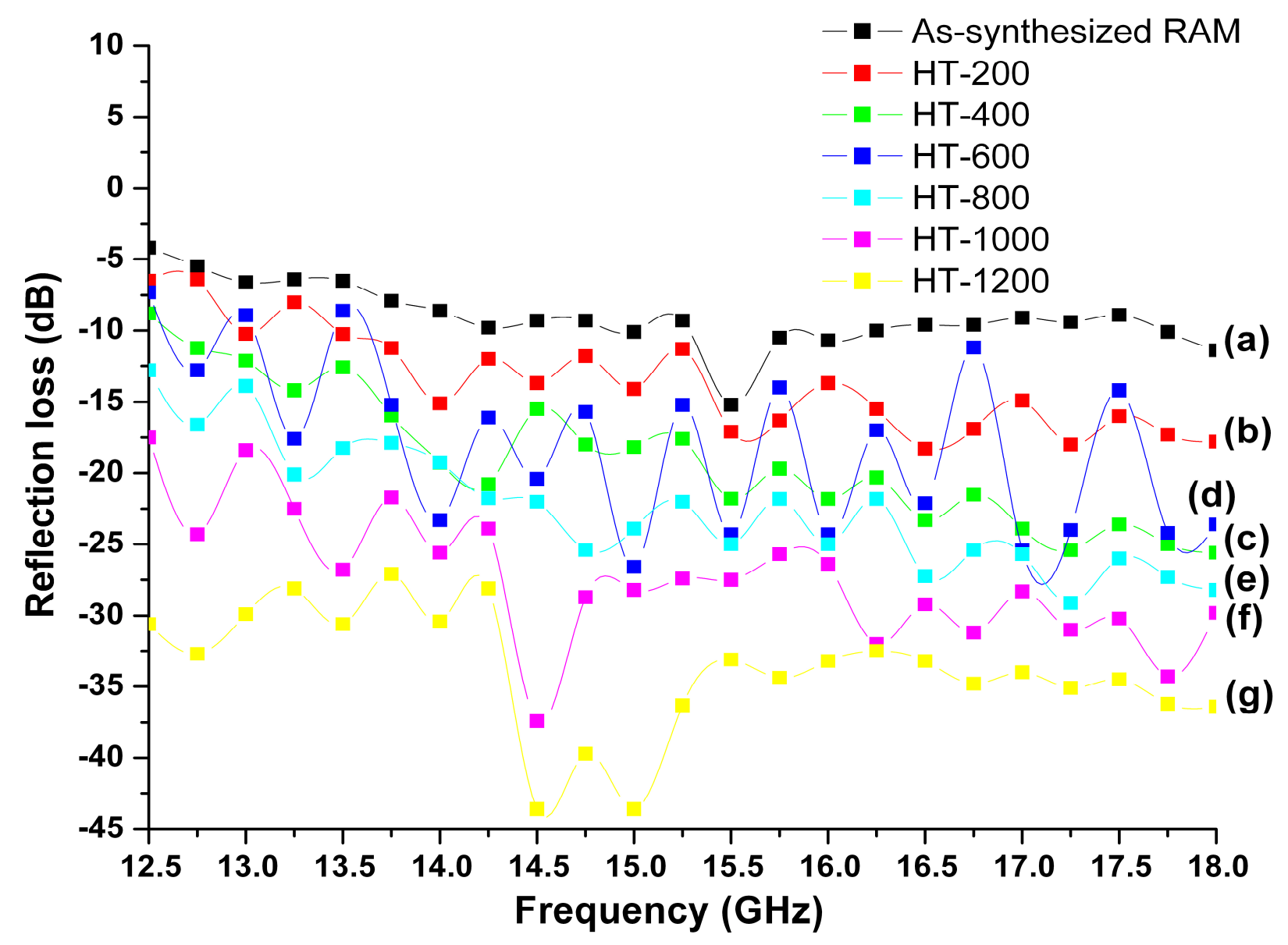

Fig. 6: Microwave absorption characteristics of nano crystals of RAM powder in Ku band (a) 'assynthesized' and vacuum annealed at (b) 200, (c) 400, (d) 600, (e) 800, (f) 1000 and (g) $1200{ }^{\circ} \mathrm{C}$. 
Further such RL enhancement mechanism can also be explained by quantum size effect in the case of as synthesized and annealed (at $200 \mathrm{oC}$ ) stable spherical nanocrystals. As it is well known that the quantum size effect in nanocrystalline makes the electronic energy level split. The spacing between adjacent energy states increases inversely with the volume of the particle. At the same time, with the decrease of the particle size, the number of incomplete molecules and the defects of surface and interface increase rapidly, which will lead to the multiplication of discrete energy levels. If the particle size of absorber is small enough and the discrete energy level spacing is in the energy range of microwave, the electron can absorb the energy as it leaps from one level to another, which may lead to the increment of attenuation.

Table 2: The effect of vacuum annealing on the refection loss (RL) characteristics in Ku-band: The range of refection loss in Ku-band (12.4-18.0 GHz), strongest RL and bandwidth of various nano crystals.

\begin{tabular}{|c|c|c|c|c|c|}
\hline \multirow{3}{*}{\multicolumn{2}{|c|}{$\begin{array}{c}\text { Temperature } \\
\left({ }^{\circ} \mathrm{C}\right)\end{array}$}} & \multicolumn{2}{|c|}{$\begin{array}{c}R L \text { in } K_{u} \text { band range } \\
\text { at }\end{array}$} & \multirow{3}{*}{$\begin{array}{l}\text { The widest RL bandwidth } \\
\text { with range } \\
\text { (in GHz) }\end{array}$} & \multirow{3}{*}{$\begin{array}{c}\text { The Strongest } \\
\text { RL } \\
\text { (in dB) }\end{array}$} \\
\hline & & $\begin{array}{l}\text { 12.4 GHz } \\
\text { (Min.) }\end{array}$ & $\begin{array}{l}\text { 18.0 GHz } \\
\text { (Max.) }\end{array}$ & & \\
\hline & & \multicolumn{2}{|c|}{ (in dB) } & & \\
\hline \multicolumn{2}{|c|}{$\begin{array}{c}80(\text { As } \\
\text { Synthesized) }\end{array}$} & -04.2 & -11.4 & $\begin{array}{l}2.00(-15.00 \text { to }-18.00) \text { and } \\
2.25(-13.00 \text { to }-15.25)\end{array}$ & $\begin{array}{c}-15.20 \\
\text { (at } 15.50 \mathrm{GHz} \text { ) }\end{array}$ \\
\hline \multirow{6}{*}{ 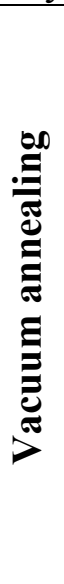 } & 200 & -06.5 & -17.8 & $\begin{array}{c}1.25 \\
(-14.50 \text { to }-15.75)\end{array}$ & $\begin{array}{c}-17.10 \\
\text { (at } 15.50 \mathrm{GHz} \text { ) }\end{array}$ \\
\hline & 400 & -8.8 & -25.6 & $1.50(-15.50$ to -17.00$)$ & $\begin{array}{c}-20.77 \\
\text { (at } 14.25 \mathrm{GHz} \text { ) }\end{array}$ \\
\hline & 600 & -7.3 & -23.6 & (Sharp metastable peaks) & $\begin{array}{c}-26.60 \\
\text { (at } 15.00 \mathrm{GHz} \text { ) }\end{array}$ \\
\hline & 800 & -12.5 & -28.2 & $1.25(-16.75$ to -18.00$)$ & $\begin{array}{c}-29.10 \\
\text { (at } 17.25 \mathrm{GHz} \text { ) }\end{array}$ \\
\hline & 1000 & -17.5 & -29.8 & $\begin{array}{c}1.50 \\
(-14.75 \text { to }-16.25)\end{array}$ & $\begin{array}{c}-37.40 \\
\text { (at } 14.50 \mathrm{GHz} \text { ) }\end{array}$ \\
\hline & 1200 & -30.6 & 36.4 & $\begin{array}{c}2.50(-15.50 \text { to }-18.00) \text { and } \\
1.75(-12.50 \text { to }-14.25)\end{array}$ & $\begin{array}{c}-43.60 \\
\text { (at } 15.00 \mathrm{GHz} \text { ) }\end{array}$ \\
\hline
\end{tabular}

When the uniform morphology in nanoscale is subsisted, the structure of crystalline may from the multiple magnetic domains to the single, and the coercive force of the material increases largely. This may lead to big hysteresis attenuation and the absorbing properties can be improved greatly [40]. Further analysis of the absorption enhancement mechanism was studied based on the electromagnetic theory and magnetization hysteresis loop measurements [43-46]. It is observed in this study and also recently reported [24] that the pyramidal faced morphology in nano scale range has shown excellent enhancement in RL in comparison to other shapes. In figure 7, effect of increasing thermal irradiation onto the $\mathrm{RL}$ in $\mathrm{Ku}$ band at the minimum $(12.4 \mathrm{GHz})$ and maximum $(18.0 \mathrm{GHz})$ frequencies and the variation nano crystal size and RL bandwidth are shown in inserted figure (b). 


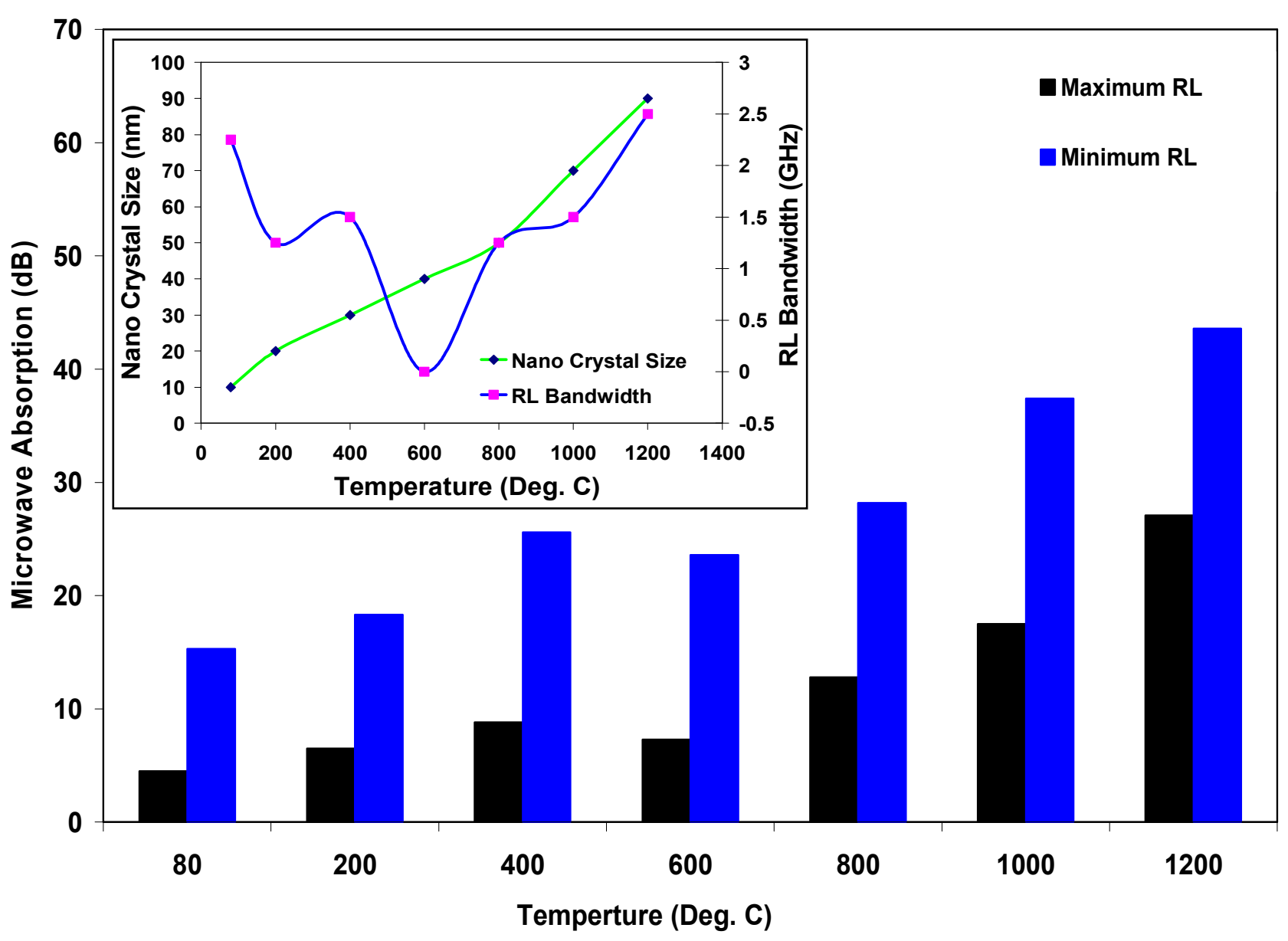

Fig. 7: The effect of increasing thermal irradiation on (a) Refection losses (microwave absorption) in $\mathrm{Ku}$ band at the minimum $(12.4 \mathrm{GHz})$ and maximum $(18.0 \mathrm{GHz})$ frequencies and inserted figure (b) the variation nano crystal size and RL bandwidth.

\section{Summary}

Uniform nano crystals of barium hexaferrite with wide size and shape distribution have been successfully synthesized using modified $\mathrm{NaCl}$ flux method. No $\alpha-\mathrm{BaFe}_{2} \mathrm{O}_{4}, \gamma-\mathrm{Fe} 2 \mathrm{O} 3$, or any other ferrite intermediate was observed during the formation that indicated the direct formation of single phase $\mathrm{BaFe}_{16} \mathrm{O}_{27}$ hexaferrite nanocrystals. With increasing annealing temperature the surface morphologies is changing and crystallanity is increasing continuously. This systematic process of nano crystal's growth $(10-90 \mathrm{~nm})$ and morphologies (spherical to pyramidal faces) evolution seen under FESEM and TEM micrographs is further explained in terms of Ostwald ripening and quantum size effect. With the increase in annealing temperature from 200 to $1200{ }^{\circ} \mathrm{C}$ the real parts, $\varepsilon^{\prime}$ and $\mu^{\prime}$ were found to increase from 7.85 to 17.69 and 12.40 to 32.72 respectively at $12.4 \mathrm{GHz}$ and the values remain stable in 14.20 to $18.0 \mathrm{GHz}$. The imaginary parts, $\varepsilon^{\prime \prime}$ and $\mu^{\prime \prime}$ almost be stable in the entire frequency range during annealing, with some fluctuations for nano crystals annealed at 600 and $800{ }^{\circ} \mathrm{C}$ due to the metastable morphologies. A significant increment from $-15.23 \mathrm{~dB}$ to $-43.65 \mathrm{~dB}$ with wide range of bandwidth in RL loss is noticed due to the symmetric morphological growth of single phase $\mathrm{BaFe}_{18} \mathrm{O}_{27}$ hexaferrite nanocrystals of pyramidal faces having high homogeneity during annealing under vacuum. 


\section{References}

[1] K.M. Lim, M.C Kim, K.A. Lee and C.G. Park: IEEE Trans. Magn. Vol. 39 (2003), p. 1836

[2] S. Sugimoto, K. Okayama and S. Kondo: Mater. Trans. JIM Vol. 39 (1998), p. 1080

[3] R. Sharma, R.C. Agarwala and V. Agarwala: Book of Abstract of $8^{\text {th }}$ International conference NANO-2006 IISc Bangalore, India, (2006), p. 11

[4] P. Singh, V.K. Babbar, A. Razdan, R.K. Puri and T.C. Goel: J. Appl. Phys. Vol. 87 (2000), p. 4362

[5] A. Quirantes, R. Plaza and A. Delgado: J. Colloid Interface Sci. Vol. 189 (1997), p. 236-241

[6] T. Ishikawa and E. Matijevic: Langmuir Vol. 4 (1988), p. 26-31

[7] D. Zabetakis, M. Dinderman and P. Schoen: Adv. Mater. Vol. 17 (2005), p. 734-738

[8] S. Watson, D. Beydoun and R. Amal: J. Photochem Photobiol A. Chem Vol. 148 (2002), p. 303313

[9] O.K. Park and Y.S. Kang: Colloid Surface A Vol. 257 (2005), p. 261-265

[10] A. Wadhawan, D. Garrett and J.M. Perez: Appl. Phys. Lett. Vol. 83 (2003), p. 2683

[11] X. Tang, B.Y. Zhao and K.A. Hu: J. Phy. Chem. of Solids Vol. 67 (2006), p. 2442-2447

[12] N. Dishovaski, A. Petkov, I. Nedkov and I. Pazkazov: IEEE Trans. Magn. Vol. 30 (1994), p. 969 971.

[13] H.T. Kwon, J.Y. Shin and J.H. Oh: J. Appl. Phys. Vol. 75 (1994), p. 6109-6111

[14] S. Sugimoto, S. Kondo and K. Okayama: IEEE Trans. Magn. Vol. 35 (1999), ～p. 3154-3156.

[15] X. Pan, G. Mu, H. Shen and M. Gu: Appl. Surf. Sci. Vol. 253 (2006), p. 4119-4122.

[16] Z.W. Liu, L.X. Phua, Y. Liu and C.K. Ong: J. Appl. Phys. Vol. 100 (2006), p. 93902.

[17] R. Sharma, R.C. Agarwala and V. Agarwala: J. Alloys Compd. (2008), doi:10.1016/j.jallcom.2007.11.141.

[18] R. Sharma, R.C. Agarwala and V. Agarwala: J. Magn. Magn. Mater. Vol. 312 (2007), p. 117125.

[19] A.P. Alivisatos: Science Vol. 271 (1996), p. 933.

[20] C. Burda, X. Chen, R. Narayanan and M.A. El-Sayed: Chem. Rev. Vol. 105 (2005), p. 1025.

[21] W. Merchan, A.V. Saveliev and L.A. Kennedy: Chem. Phys. Lett. Vol. 422 (2006), p. 72.

[22] V. Pachauri, C. Subramaniam and T. Pradeep: Chem. Phys. Lett. Vol. 423 (2006), p. 240.

[23] S.R. Nicewarner-Pena, G.P. Freeman, B.D. Reiss, L. He, D.J. Pena, I.D. Walton, R. Cromer, C.D. Keating and M.J. Natan: Science Vol. 294 (2001), p. 137. 
[24] R. Sharma, R.C. Agarwala and V. Agarwala: Materials Letters (2007), doi: 10.1016/j.matlet.2007.11.076.

[25] M. Li, H. Schnablegger and S. Mann: Nature Vol. 402 (1999), p. 393.

[26] L. Gou and C. J. Murphy: Nano Lett. Vol. 3 (2003), p. 231.

[27] M. Cao, Y. Wang, C. Guo, Y. Qi and C. Hu: Langmuir Vol. 20 (2004), p. 4784.

[28] T. Matsumoto, M. Okazaki, M. Inoue, Y. Hamada, M. Taira and J. Takahashi: Biomaterials Vol. 23 (2003), p. 2241.

[29] R. Gonzalez-McQuire, J.Y. Chane-Ching, E. Vignaud, A. Lebugle and S. Mann: J. Mater. Chem. Vol. 14 (2004), p. 2277.

[30] B.T. Shirk and W.R. Bussem: J. Am. Ceram. Soc. Vol. 53 (1970), p. 192.

[31] K. Haneda, C. Miyakawa and H. Kojima: J. Am. Ceram. Soc. Vol. 57 (1974), p. 354.

[32] M. Vallet-Regi, P. Rodriguez, X. Obradors et al.: J. Phys. (Paris) Vol. 46 (1985), p. 335.

[33] E. Matijevic: J. Colloid. Interface Sci., Vol. I17 (1987), p. 593.

[34] Z.X. Tang, S. Naris and C.M. Sorensen: J. Magn. Magn. Mater. Vol. 80 (1989), ～p. 285.

[35] G.L. Messing, S.C. Zhang and G.V. Jayanthi: J. Am. Ceram.Soc. Vol. 76 (1993), p. 2707.

[36] V.V. Pankov, M. Pernet, P. Gelani and P. Mollard: J. Magn. Magn. Mater. Vol. 120 (I993), p. 69.

[37] W. Z. Ostwald: Phys. Chem. Vol. 34 (1900), p. 495.

[38] P.A. Miles, W.B. Westphal and A.V. Hippel: Rev Mod Phys Vol. 29 (1957), p. 279

[39] K. Ishino, Y. Narumiya: Ceram Bull Vol. 66 (1987), p. 1469.

[40] S. Ruan, B. Xu, H. Suo, F. Wu, S. Xiang and M. Zhao: J. Magn. Magn. Mater. Vol. 212 (2000), p. 177.

[41] J.R. Liu, M. Itoh, T. Horikawa, K. Machida, S. Sugimoto and T.J. Maeda: J. Appl. Phys. Vol. 98 (2005), p. 54305.

[42] R.C. Che, C.Y. Zhi, C.Y. Liang and X.G. Zhou: Appl. Phys. Lett. Vol. 88 (2006), p. 33105.

[43] F. Gazeau, E. Dubois, M. Hennion, R. Perynski and Y. Raikher: Europhys. Lett. Vol. 40 (1997), p. 575 .

[44] J.G. Guan, W. Wang, R.Z. Gong, R.Z. Yuan, L.H. Gan and K.C. Tam: Langmuir Vol. 18 (2002), p. 4189.

[45] R.H. Kodama and A.E. Berkowitz: Phys. Rev. B Vol. 59 (1999), p. 6321.

[46] K.I. Kobayashi, T. Kimura, H. Sawada, K. Terakura and Y. Tokura: Nature (London) Vol. 395 (1998), p. 677. 